\title{
Viral infections of the liver in childhood
}

\author{
A. J. ZuCKerman \\ M.D., D.Sc., M.R.C.Path., Dip. Bact. \\ London School of Hygiene and Tropical Medicine, London
}

\begin{abstract}
Summary
Hepatitis A and hepatitis B viruses and yellow fever virus are the most important causes of acute inflammation of the liver. Hepatitis is also frequently associated with other common viral infections such as cytomegalovirus (human herpesvirus 5) and EB virus (human herpesvirus 4). In addition, there are a number of viruses which occasionally display increased hepatotropism producing a clinical picture which is similar to classical hepatitis.
\end{abstract}

THE common definition of viral hepatitis is acute inflammation of the liver caused by at least two immunologically distinct infectious agents, named hepatitis $\mathrm{A}$, the aetiological agent of infectious, epidemic or short-incubation hepatitis (hepatitis A) and virus $B$ which is responsible for so-called serum hepatitis or long-incubation hepatitis (hepatitis B). Inflammation of the liver caused by yellow fever virus, as well as the hepatitis frequently associated with other common viral infections such as cytomegalovirus (human herpesvirus 5) and EB virus (human herpesvirus 4) are generally not included in this definition. In addition, there are a number of viruses which do not normally cause liver damage but nevertheless display occasionally increased hepatotropism, resulting sometimes in jaundice and a clinical picture which is similar to classical hepatitis. This group of viruses includes adenoviruses, rubella virus, paramyxoviruses, a number of enteroviruses particularly coxsackie $A$ and $B$ viruses, herpes simplex virus and others (reviewed by Zuckerman, 1970). Indeed the isolation of a wide variety of viruses over a period of some years from patients with hepatitis resulted in a heterogeneous collection of 'candidate hepatitis viruses', none of which have since been shown to be consistently or causally associated with hepatitis.

Correspondence: Professor A. J. Zuckerman, Hepatitis Research Unit, Department of Microbiology, London School of Hygiene and Tropical Medicine, Keppel Street (Gower Street), London, WC1E 7HT.

\section{Viral hepatitis type $A$}

Hepatitis A is a major public health problem, occurring endemically in all parts of the world, with frequent reports of minor or major epidemics. The commonest mode of transmission is faecal-oral spread, primarily by person to person contact. The $\mathrm{O}$ faecal contamination of water and food have resulted in many large commonsource outbreaks. Hepatitis A can also be transmitted parenterally, by blood and probably also by blood products. Other routes of infection are also possible but as yet uf $\varphi$ proven. Sub-clinical cases are common and a possibe source of spread of infection. The incubation perie is $3-5$ weeks with a mean of 28 days.

The epidemiology, pathology, the efforts to isolate and identify the virus in tissue and organ cultures and by other laboratory methods, transmission experiments to human volunteers and the control of $\overrightarrow{\vec{P}}$ hepatitis A, have been extensively reviewed (WHO 을 Report, 1964; Zuckerman, 1970; Krugman and Giles, 1970; Zuckerman, 1972).

\section{Hepatitis $A$ antigens}

The Milan antigen (also referred to in the past as Epidemic-Hepatitis-Associated-Antigen), detected $\delta$ by gel diffusion in the serum of a large proportion of $₹$ patients during the acute phase of hepatitis A (Del 윽 Prete et al., 1970), has since been shown to be a serum lipoprotein, possibly abnormal and lacking specificity for type A hepatitis (Taylor et al., 1972). In other studies, Ferris et al. (1970) reported the $\sigma$ presence of an antigen in extracts of faeces obtained $N$ from about $50 \%$ of patients admitted to hospital $\underset{\omega}{N}$ during the first 3 weeks of hepatitis A infection. The antigen was also found in faecal extracts of $2 \%$ of control patients. Examination by electron micro- $\frac{\mathcal{\complement}}{\Phi}$ scopy after negative staining revealed the presence $\stackrel{?}{?}$ of two virus-like particles in the faecal extracts. One $\square$ type of particle measured $15-20 \mathrm{~nm}$ in diameter $\bar{O}$

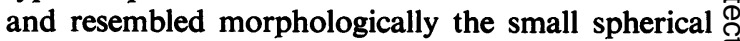
particles of hepatitis B antigen. The second group of $\frac{\mathbb{Q}}{\mathbb{Q}}$ 
particles measured 40-45 $\mathrm{nm}$ in diameter and resembled the large double-shelled spheroidal hepatitis B antigen particles, although they were more pleomorphic. These particles were found by direct electron microscopical examination of faecal extracts, in gel precipitin lines produced by reacting faecal extracts with animal antiserum, in sucrose gradient fractions of positive faecal extracts reacted with antiserum and in immune aggregates from faecal extracts. The tubular forms, usually found with hepatitis B antigen, were not seen in association with the faecal antigen. The serological cross-reaction of the larger particulate component of the faecal antigen with hepatitis B antigen was of interest. However, the faecal antigen has not yet been prepared in a sufficiently pure form so that the antisera raised in animals are not entirely specific and the antisera behave erratically (Ferris, 1972). Further studies of this antigen are required.

\section{Studies of hepatitis $A$ by electron microscopy}

Attempts to demonstrate the hepatitis A virus by electron microscopy have not been successful. The significance of coronavirus-like and paramyxoviruslike particles found after negative staining and electron microscopy in the sera of a number of patients with hepatitis (Zuckerman, Taylor and Almeida, 1970; Deinhardt et al., 1970; Sirtori, 1970; Apodaca et al., 1970; Zawrocka-Wrzolkowa, 1972; Stannard et al., 1973) remains unknown. Coronavirus-like particles were found by Becker and Larsson in 22 serum specimens from fourteen patients with hepatitis, in nine of whom hepatitis B antigen was also detected. The virus-like particles possessed a characteristic fringe of surface projections, but these were not club-shaped as in the case of the coronaviruses and a ribonucleoprotein helix could not be demonstrated. The majority of the particles were provisionally classified as fragments of inner mitochondrial membrane and may in fact be membrane vesicles (Zuckerman, 1973).

Stannard et al. (1973) studied by electron microscopy the distribution of the morphological types of hepatitis B antigen in the plasma of fifty apparently healthy blood donors, in whom the antigen was detected by counter-immunoelectrophoresis during routine screening, and also in serial samples from two patients with hepatitis B infection. Hepatitis B antigen particles were found in forty-seven out of the fifty blood donor samples and in both patients with acute hepatitis B. In addition, large particles resembling coronaviruses or paramyxoviruses were found frequently in most of the blood donor samples and in both patients. These coronavirus-like particles usually appeared in clusters apparently linked by antibody. All three seropositive donors in whom the antigen was not visualized by electron microscopy also had these particles in their plasma. It was noted that whatever the nature and significance of the large particles it may be important that they were not only seen frequently, often in aggregates, but they were also commonly seen in small numbers in many of the plasma samples obtained from apparently healthy carriers of hepatitis B antigen.

However, in the absence of other markers and particularly until specific serological tests have been carried out, it is not possible to ascribe any definite role to members of the coronavirus group in human hepatitis. None of the observations reported to date prove that the coronavirus-like structure visualized by electron microscopy are specifically associated with or are causally related to hepatitis $A$, and it may well be that such particles are fragments of cell organelles arising in the course of liver damage, including hepatitis B infection (Zuckerman, 1972).

\section{Transmission of hepatitis $A$ to non-human primates}

Attempts have been made for many years to propagate human hepatitis viruses outside human volunteers. The observation of hepatitis $\mathrm{A}$ among human handlers of potential astronaut chimpanzees in 1961-62 and subsequent reports of more than forty small clusters of cases of viral hepatitis in human beings in close contact with recently imported young monkeys, revived interest in experimental transmission studies to non-human primates. However, the infection was not transmitted consistently from animal to animal and interpretation was further complicated by spontaneous hepatitis in some monkeys.

Working on the assumption that primates which have little or no contact with man are unlikely to have acquired immunity to the human hepatitis virus, Deinhardt et al. (1967) have made use of marmosets, a species of small South American monkey. These monkeys have minimal contact with man and serological surveys of antibody have confirmed that naturally acquired infection to common human viruses is rare. Biochemical and histological changes compatible with hepatitis were found after the inoculation of acute phase serum of plasma from patients with acute hepatitis A in two species of marmosets, Saguinus nigricollis and $S$. fuscicollis. Liver damage, without clinical evidence of infection, was produced regularly during five serial transmissions from marmoset to marmoset. Further evidence that marmosets of the species Saguinus mystax are susceptible to human hepatitis $\mathrm{A}$, but not to human hepatitis B, was provided by Lorenz et al. (1970) who reported the induction of biochemical and histological evidence of liver damage after injecting marmosets with serum derived from a pool of sera obtained from volunteers who were suffering from experimentally transmitted hepatitis A. 
More recently, Mascoli et al. (1973) inoculated intravenously 274 marmosets, mainly of the species Saguinus mystax and a few S. nigricollis, with blood from human cases of hepatitis A or heptatitis B. It was found that the indispensable element for the induction of hepatitis in marmosets was the introduction of blood from patients with hepatitis A. As an in-built control, serial passage was carried out in marmosets of a pool of sera obtained prior to inoculation from marmosets in which the hepatitis A agent was subsequently propagated. Spontaneous hepatitis in marmosets was not encountered.

Blood specimens from five out of seven patients with acute hepatitis A in Costa Rica induced hepatitis in the marmosets. Blood samples taken from patients 22-29 days before the onset of illness yielded negative findings in seventy marmosets. Pools containing samples obtained during the acute illness or during convalescence (29-113 days after the onset of illness) caused hepatitis in twenty-four of 119 animals. The agent of hepatitis $A$ was passaged successfully four times and it was concluded that the marmoset is highly reliable for detecting, propagating and studying human hepatitis $\mathrm{A}$.

Provost et al. (1973) used the CR 326 strain of hepatitis A virus of the fourth passage in marmosets for determining the physical and chemical properties of the agent. Filtration data showed the particle size to be in the range of $>25 \mathrm{~nm}<50 \mathrm{~nm}$. The virus was stable to ether and stable in acid (pH 3.0 for $3 \mathrm{hr}$ at room temperature) and resisted heat for $1 \mathrm{hr}$ at $60^{\circ} \mathrm{C}$ in sealed glass containers. The results were evaluated by intravenous inoculation of $1.0 \mathrm{ml}$ of the treated preparations to each of twelve marmosets per sample.

Susceptibility of two species of marmosets to hepatitis A was also evaluated. It was found that $80 \%$ of Saguinus mystax developed hepatitis by the eighth week after inoculation compared with only $33 \%$ of Saguinus nigricollis.

A pool of sera of the fourth passage of strain CR 326 in S. mystax marmosets was used for serum neutralization tests. The tests were carried out with eight paired sera from patients with hepatitis $A$ and two patients with hepatitis B. These included paired sera under code from three human volunteers inoculated with the MS-1 strain of hepatitis A and one inoculated with the MS-2 strain of hepatitis B. In addition, three samples of pooled human immune globulin were used for neutralization studies. It was found that all patients with classical hepatitis A infection developed antibody which neutralized the CR 326 marmoset strain; but there was no such antibody response in patients with hepatitis B infection. All three samples of human immune globulin neutralized CR 326. Neutralization was highly effective since marmosets inoculated with the neutralized virus (serum-antiserum mixture) re- $\frac{\mathbb{\Phi}}{\mathbb{D}}$ mained susceptible to reinfection by $C R \quad 326$. In $\cong$ contrast marmosets given non-neutralized virus ${ }^{\complement}$. mixture were immune to reinfection. The precise $\vec{\Rightarrow}$ limits of sensitivity and reliability of this serum? neutralization test are as yet undetermined, in view of the large numbers of assays which are required.

Holmes et al. (1973) reported the results of attempts to neutralize the infection in marmosets with con- 음 valescent human hepatitis A serum. Acute phasecs serum or plasma from human volunteers inoculated $\vec{\circ}$ with the MS-1 strain of human hepatitis A, or the infectious fractions of such serum or plasma pre- $\vec{\sigma}$ pared by density gradient separation in caesium: chloride, were mixed in a 1:1 ratio with pre-inocula- $-\frac{0}{3}$ tion or convalescent serum from one of the volunteers. The mixtures were incubated for $16-18 \mathrm{hr}$ at $4^{\circ} \mathrm{C}$. and then $0.5 \mathrm{ml}$ inoculated intravenously under code ${ }_{\infty}^{\circ}$ into groups of marmosets, $S$. nigricollis and $S .+$ fuscicollis. The convalescent serum neutralized $\mathbb{W}_{\infty}$ almost completely the infectivity of the acute serum ${ }^{\infty}$ or the infectious fractions prepared from it, whereas ${ }_{-}^{\circ}$ infectivity was unaffected by incubation with human $\vec{C}_{\bar{C}}$ serum albumin or by incubation with the preinoculation serum.

The availability of the marmoset model is $\mathrm{gf} \overrightarrow{\mathrm{e}}$ practical importance for investigating the patke- + genesis of hepatitis $A$ and for identifying the pr-口 perties of the virus.

\section{Cytomegalovirus}

Cytomegalovirus (human herpesvirus 5) is widely $\stackrel{\overbrace{}}{\Rightarrow}$ disseminated throughout the world and inapparento infection is common. The highest infection rates are found in early infancy, in adolescents and in young adults. Thus $5-10 \%$ of children in London acquire antibodies by the age of 2 years, up to $20 \%$ have 3 antibodies by the age of 15 years and between the age of 15 and 30 years as many as $50-60 \%$ have 3 . antibodies (reviewed by Stern, 1972). Primary cytomegalovirus infection is followed by persistent latent infection.

The outstanding pathological changes observed? in all forms of the infection are the presence of greatly enlarged inclusion-bearing cells which are pathognomonic of the disease. The inclusions are located primarily in epithelial cells but may also ben found in endothelial and connective tissue cells. InN the generalized disease, hepatitis is usually present ${ }_{0}^{\omega}$ and the liver is grossly enlarged. The cytomegalic inclusion cells are found in the epithelium of the small bile ducts but these may be sparse when theres? is severe hepatitis. Necrotic foci, degenerate hepatocytes, biliary stasis and multinucleated giant hepatico cells may be present. There is usually heavy cellularब infiltration of the portal tracts, but this varies with 
the severity and duration of liver involvement; fibrosis may be present (Taylor, 1970).

Most primary infections with cytomegalovirus are subclinical, yet this virus may cause dysfunction of the liver at all ages. However, the most severe and most clearly defined clinical syndrome, although also the least common, is neonatal cytomegalic inclusion disease. This syndrome is usually the result of a primary, subclinical or mild clinical infection of the mother with cytomegalovirus during pregnancy. The important clinical features, presenting at birth or shortly afterwards, include jaundice, thrombocytopenia, hepatosplenomegaly, haemolytic anaemia and evidence of brain damage which may be associated with microcephaly. About a third of the cases present as neonatal hepatitis (Stern, 1972) with jaundice of the obstructive type appearing usually within $24 \mathrm{hr}$ of birth. The jaundice may persist for a number of weeks or months and hepatomegaly is invariable.

Milder forms of the neonatal disease are much commoner, presenting with symptoms which include low birth weight, jaundice, hepatosplenomegaly, purpura and pneumonitis, with or without involvement of the central nervous system.

Acquired cytomegalovirus infection up to the age of about 5 years is of the chronic type, although in most cases it is probably subclinical. Abnormal liver function tests, including hepatomegaly, have been noted in apparently healthy children excreting cytomegalovirus in the urine or in the throat (Hansaw et al., 1965; Stern, 1968). Occasionally liver dysfunction may be found in association with a febrile illness, with or without transient jaundice, in a child with recent serological evidence of infection with cytomegalovirus. There is, however, little evidence that cytomegalovirus infection acquired in early childhood leads to chronic liver disease in children (Stern, 1972).

\section{EB virus}

Dunnet (1963) remarked that 'hepatitis occurs in practically every case (of infectious mononucleosis) and probably should now be regarded not so much as a complication as part of the syndrome of infectious mononucleosis'. The aetiological role of EB virus (human herpesvirus 4) in the pathogenesis of infectious mononucleosis is gaining wide acceptance. The evidence obtained from the results of recent prospective studies has been summarized by Evans (1972): infectious mononucleosis occurs only in persons lacking antibody to EB virus; persons with EB virus antibody are immune to clinical illness; the syndrome of infectious mononucleosis, which is almost always associated with heterophil-antibody, is the only frank clinical manifestation of EB virus infection as yet recognized in young adults; no other infectious agent is associated with heterophilantibody positive infectious mononucleosis; and infectious mononucleosis is not very contagious even in susceptible close contacts. Further evidence is provided by the demonstration of EB virus in cultured lymphocytes by electron microscopy and cultures of peripheral lymphocytes; by the presumed isolation of a virus from throat washings of patients with infectious mononucleosis and by the demonstration of $\mathrm{EB}$ virus-specific IgM in the acute illness.

In Western Europe and North America 50-60\% of children have acquired antibodies to EB virus by the age of 5 years and the incidence of antibodies may be $80-90 \%$ or more by the age of 20 years. In developing non-industrialized communities antibody may be present in nearly $90 \%$ of young children. The vast majority of infections, particularly in children, are largely subclinical, whereas the full clinical picture of 'glandular fever' is a characteristic syndrome in adolescents and young adults.

As far as the liver is concerned, the degree of hepatocellular damage is unrelated to the severity of the infection. Clinical jaundice is present in 5-15\% of patients. Histologically, the most prominent finding is infiltration of the sinusoids and portal tracts with large mononuclear cells. The sinusoids and portal tracts may be packed with leucocytes and lymphocytes simulating leukaemic infiltration. Necrotic lesions tend to be focal, there is no surrounding inflammatory cell reaction and there is evidence of proliferation of the Kupffer cells. Intense regeneration of hepatic cells follows and this is out of proportion to the extent of cellular necrosis. Cirrhosis of the liver is not a complicating sequel of infectious mononucleosis.

\section{Rubella virus}

Clinically, rubella is a mild infection and its importance lies in the congenital malformations which may result from infection of the mother during the first trimester of pregnancy. Cooper et al. (1965) estimated the incidence of hepatitis in the expanded congenital rubella syndrome, which followed the 1964 epidemic, to be about $20 \%$. The severity of the hepatic lesions in congenital rubella varies from focal necrosis in infants with clinically inapparent liver disease to jaundice and massive hepatocellular necrosis. Giant-cell hepatitis has been described in some patients and portal fibrosis and severe cholestasis in others. The prognosis of rubella hepatitis is difficult to evaluate at present. There may be complete resolution of the hepatic lesion and only mild hepatic changes have been reported in the liver of a few infants who died early in the postnatal period. However, rubella virus may also be a cause of cirrhosis of the liver in childhood (Watson, 1952; Stern and Williams, 1966; Sherlock, 1968). There 
may also be an aetiological association between some cases of biliary atresia and viruses, such as rubella virus, which are capable of causing hepatitis in utero (Strauss and Bernstein, 1968).

\section{Other viruses}

Many other viruses which do not normally cause liver damage may sometimes produce a clinical picture which is similar to classical hepatitis. In general, however, most of these hepaticomimetic viruses seem to be able to induce icteric hepatitis only occasionally outside the neonatal period. Viruses which have been implicated include various adenovirus serotypes, paramyxoviruses, herpes simplex virus and enteroviruses (particularly coxsackie viruses groups $\mathbf{A}$ and $\mathbf{B})$ and their significance in infections of the liver has been reviewed in detail by Mosley (1970) and by Zuckerman (1970).

\section{Acknowledgments}

The work on viral hepatitis at the London School of Hygiene and Tropical Medicine is supported by generous grants from the Medical Research Council, the World Health Organization (Dr W. Chas. Cockburn), Pfizer Ltd and the Wellcome Trust.

\section{References}

Apodaca, J., Lange, W., Tochtermann, G. \& Kohler, H. (1970) Nachweis von virusähnlichen Partikeln im Serum von Affen mit experimentell erzeugter infektiöser Hepatitis. Zentralblatt für Bakteriologie, Parasitenkunde, Infektionskrankheiten und Hygiene. I. Abteilung: Originale, 214, 480.

Cooper, L.Z., Green, R.H., Krugman, S., Giles, J.P. \& MIRICK, G.S. (1965) Neonatal thrombocytopenic purpura and other manifestations of rubella contracted in utero. American Journal of Diseases of Children, 110, 416.

Deinhardt, F., Holmes, A.W., Capps, R.B. \& Popper, H. (1967) Studies on the transmission of human viral hepatitis to marmoset monkeys. The Journal of Experimental Medicine, 125, 673.

Deinhardt, F., Holmes, A.W., Wolfe, L. \& Junge, U. (1970) Transmission of viral hepatitis to nonhuman primates. Vox Sanguinis, 19, 261.

Del Prete, S., Costantino, D., Doglia, M., Grazinna, A., AJdukiewiCz, A., Dudley, F.J., Fox, R.A. \& Sherlock, S. (1970) Detection of a new serum-antigen in three epidemics of short-incubation hepatitis. Lancet, ii, 579.

DUNNET, W.N. (1963) Infectious mononucleosis. British Medical Journal, 1, 1187.

EvaNs, A.S. (1972) Infectious mononucleosis and other mono-like syndromes. New England Journal of Medicine, 286, 836.

Ferris, A.A. (1972) Antigen in infectious hepatitis. British Medical Bulletin, 28, 131.

Ferris, A.A., Kaldor, J., Gust, I.D. \& Cross, G. (1970) Faecal antigen in viral hepatitis. Lancet, ii, 243.

Hanshaw, J.B., Betts, R.F., Simon, G. \& Boynton, R.C. (1965) Acquired cytomegalovirus infection. Association with hepatomegaly and abnormal liver-function tests. New England Journal of Medicine, 272, 602.

Holmes, A.W., Deinhardt, F., Wolfe, L., Froesner, G., Peterson, D., Casto, B. \& Conrad, M.E. (1973) Specific neutralization of human hepatitis type $A$ in marmoset monkeys. Nature, 243, 419.
Krugman, S. \& GiLes, J.P. (1970) Viral hepatitis. New light on an old disease. Journal of the American Medical Association, 212, 1019.

Lorenz, D., Barker, L., Stevens, D., Peterson, M. \& $\overrightarrow{\vec{\sim}}$ KirSCHSTEIN, R. (1970) Hepatitis in the marmoset, Saguinus mystax. Proceedings of the Society for Experimental Biology and Medicine, 135, 348.

Mascoli, C.C., ItTensohn, O.L., Villarejos, V.M., $\frac{\bar{\omega}}{\stackrel{D}{\sigma}}$ Arguedas, J.A., Provost, P.J. \& Hilleman, M.R. (1973) $\mathbb{\oplus}$ Recovery of hepatitis agents in the marmoset from human $\frac{2}{\Omega}$ cases occurring in Costa Rica. Proceedings of the Society $\infty$ for Experimental Biology and Medicine, 142, 276.

MosLEy, J.W. (1970) Viral hepatitis: Recent studies of $\stackrel{-}{-}$ etiology. In: Progress in Liver Disease volume III (Ed. by $\vec{\omega}$ H. Popper and F. Schaffner), pp. 252-268. Grune \& Stratton, New York.

Provost, P.J., ITtensohn, O.L., Villarejos, V.M., Argeudas, J.A. \& Hilleman, M.R. (1973) Etiologic relationship of marmoset-propagated CR 362 hepatitis A G virus to hepatitis in man. Proceedings of the Society for if Experimental Biology and Medicine, 142, 1257.

SHERLOCK, S. (1968) Congenital rubella syndrome. In: $\dot{\omega}$ Diseases of the Liver and Biliary System, pp. 525-526. W్ Blackwell Scientific Publications, Oxford.

SIRTORI, C. (1970) Virus-like particles in infectious hepatitis. Lancet, ii, 824.

Stannard, L.M., Moodie, J., Keen, G.A. \& Kipps, A. (1973) Electron microscopic study of the distribution of the $\vec{D}$ Australia antigen in individual sera of 50 serologically positive blood donors and two patients with seruf $\vartheta$ hepatitis. Journal of Clinical Pathology, 26, 209.

STERN, H. (1968) Isolation of cytomegalovirus and clinici manifestations of infection at different ages. Brit $\stackrel{\text { 胥 }}{+}$ Medical Journal, 1, 665.

STERN, H (1972) Cytomegalovirus and EB virus infections of the liver. British Medical Bulletin, 28, 180.

STERN, H. \& Williams, B.M. (1966) Isolation of rubella $\stackrel{D}{\triangle}$ virus in a case of neonatal giant cell hepatitis. Lancet, $i, \overrightarrow{\overrightarrow{\vec{A}}}$ 293.

Strauss, L. \& Bernstein, J. (1968) Neonatal hepatitis in congenital rubella. A histopathological study. Archives of Pathology, 86, 317.

TAYLOR, P.E. (1970) Cytomegalic inclusion disease. In:흠 Virus Diseases of the Liver (By A. J. Zuckerman), pp. 127-139. Butterworth, London.

TAYlor, P.E., Almeida, J.D., Zuckerman, A.J. \& LeaCh, J.A. (1972) Relationship of Milan antigen to abnormal serum lipoprotein. American Journal of Diseases of Children, 123, 329.

WATSON, J.R.H. (1952) Hepatosplenomegaly as a complica-음 tion of maternal rubella. Medical Journal of Australia, 1, 516. World Health Organization (1964) Technical Report
Series No. 285. Geneva.

ZAWrockA-Wrzolkowa, T. (1972) Liver cell nuclei during $N$ viral hepatitis. Beiträge zur Pathologie, 146, 187.

ZuCKerman, A.J. (1970) In: Virus Diseases of the Liver. W Butterworth, London.

Zuckerman, A.J. (1972) In: Hepatitis-Associated Antigen ando Viruses. North Holland, Amsterdam.

ZuCKerman, A.J. (1973) Australia antigen. Archives Fran- $\stackrel{\mathscr{C}}{?}$ caises des Maladies de l'Appareil Digestif, 62, 160.

Zuckerman, A.J., TAylor, P.E., \& Almeida, J.D., (1970) Presence of particles other than the Australia-SH antigen $\mathbb{D}$ in a case of chronic active hepatitis with cirrhosis. British $\frac{O}{\mathbb{D}}$ Medical Journal, 1, 262. 